\title{
Analysis and Reconstitution of the Menaquinone Biosynthesis Pathway in Lactiplantibacillus plantarum and Lentilactibacillus buchneri
}

\author{
Nisit Watthanasakphuban ${ }^{1,2}$, Ludovika Jessica Virginia ${ }^{1}$, Dietmar Haltrich ${ }^{1}\left(\mathbb{D}\right.$ and Clemens Peterbauer ${ }^{1, *}$ \\ 1 Department of Food Sciences and Technology, BOKU-University of Natural Resources and Life Sciences, \\ Muthgasse 18, 1190 Vienna, Austria; faginsw@ku.ac.th (N.W.); jessica.virginia@boku.ac.at (L.J.V.); \\ dietmar.haltrich@boku.ac.at (D.H.) \\ 2 Department of Biotechnology, Faculty of Agro-Industry, Kasetsart University, Chatuchak, \\ Bangkok 10900, Thailand \\ * Correspondence: clemens.peterbauer@boku.ac.at; Tel.: +43-1-47654-75212
}

check for updates

Citation: Watthanasakphuban, N.; Virginia, L.J.; Haltrich, D.; Peterbauer, C. Analysis and Reconstitution of the Menaquinone Biosynthesis Pathway in Lactiplantibacillus plantarum and Lentilactibacillus buchneri. Microorganisms 2021, 9, 1476. https://doi.org/10.3390/ microorganisms 9071476

Academic Editor: Franca Rossi

Received: 18 June 2021

Accepted: 8 July 2021

Published: 9 July 2021

Publisher's Note: MDPI stays neutral with regard to jurisdictional claims in published maps and institutional affiliations.

Copyright: (c) 2021 by the authors. Licensee MDPI, Basel, Switzerland. This article is an open access article distributed under the terms and conditions of the Creative Commons Attribution (CC BY) license (https:/ / creativecommons.org/licenses/by/ $4.0 /)$.

\begin{abstract}
In Lactococcus lactis and some other lactic acid bacteria, respiratory metabolism has been reported upon supplementation with only heme, leading to enhanced biomass formation, reduced acidification, resistance to oxygen, and improved long-term storage. Genes encoding a complete respiratory chain with all components were found in genomes of L. lactis and Leuconostoc mesenteroides, but menaquinone biosynthesis was found to be incomplete in Lactobacillaceae (except $L$. mesenteroides). Lactiplantibacillus plantarum has only two genes (men $A, m e n G)$ encoding enzymes in the biosynthetic pathway (out of eight), and Lentilactobacillus buchneri has only four (menA, menB, menE, and $m e n G)$. We constructed knock-out strains of L. lactis defective in menA, menB, menE, and menG (encoding the last steps in the pathway) and complemented these by expression of the extant genes from Lactipl. plantarum and Lent. buchneri to verify their functionality. Three of the Lactipl. plantarum biosynthesis genes, IpmenA1, Ipmen G1, and lpmen G2, as well as lbmenB and lbmen G from Lent. buchneri, reconstituted menaquinone production and respiratory growth in the deficient L. lactis strains when supplemented with heme. We then reconstituted the incomplete menaquinone biosynthesis pathway in Lactipl. plantarum by expressing six genes from L. lactis homologous to the missing genes in a synthetic operon with two inducible promoters. Higher biomass formation was observed in Lactipl. plantarum carrying this operon, with an $\mathrm{OD}_{600}$ increase from 3.0 to 5.0 upon induction.
\end{abstract}

Keywords: menaquinone; demethlymenaquinone; respiration; lactic acid bacteria

\section{Introduction}

Lactic acid bacteria (LAB) are non-respiring, fermentative anaerobic oxygen-tolerant bacteria and are typically cultivated under (micro)anaerobic conditions. In several LAB including $L$. lactis and L. mesenteroides, a respiration-like behavior was observed upon addition of heme to the medium [1], and actual respiration was shown in L. lactis [2] and L. mesenteroides [3,4], leading to stimulated aerobic growth, reduced acidification, improved growth efficiency, and stress resistance [2]. Furthermore, the addition of Lacticaseibacillus casei cultures grown under respiratory conditions led to improved organoleptic and nutritional properties of both cheddar cheese as well as sourdough $[5,6]$. The respiratory chain components of LAB are dehydrogenases, a heme-dependent cytochrome oxidase, and quinones as the electron shuttle $[3,7,8]$. For Gram-positive bacteria, vitamin $\mathrm{K} 2$ (menaquinone) is the sole quinone in the electron transport chain [9]. Menaquinone shuttle two electrons from electron donors and transfer them to the electron acceptor (heme) [9]. Since LAB do not produce heme [10] due to an incomplete heme biosynthesis pathway [11], it must be supplemented for all species. Supplementation of both heme and menaquinone leads to respiratory behavior in several additional species, indicating an incomplete respiratory chain lacking quinones [1,11]. 
In silico studies of $\mathrm{LAB}$ genomes revealed that the necessary genes for the formation of $b d$-type cytochrome oxidase (cydABCD) are widespread and are absent only in Lactobacillus acidophilus, Lactobacillus delbrueckii, and Lactobacillus helveticus, as well as in Latilactobacillus curvatus and Latilactobacillus sakei $[1,3]$. Genes that encode a complete menaquinone biosynthesis pathway are found in some L. lactis [12,13], but not Lactobacillaceae (with the exception of L. mesenteroides). The genome of Lactipl. plantarum WCFS1 contains only $m e n A$ and $m e n G$ genes, encoding the last two (of eight) pathway enzymes [14], and Lent. buchneri DSM 20057 contains menE, men $B$, men $A$, and $m e n G$, with the genes encoding the first four steps (menFDHC) in the pathway being absent. Both genomes contain the genes for the cytochrome oxidase (data from Joint Genome Institute, www.jgi.doe.gov, 9 May 2016, pathway analysis using the pathway maps of the Kyoto Encyclopedia of Genes and Genomes, www.genome.jp, 9 May 2016).

In this study, we determined the functionality of the remaining menaquinone pathway genes in Lactipl. plantarum WCFS1 and Lent. buchneri DSM 20057 using classical methods of gene inactivation and genetic complementation for the investigation of a biosynthetic pathway and analyzed their growth behavior under aerobic conditions with heme supplementation.

\section{Materials and Methods}

\subsection{Bacterial Strains, Plasmids, Primers, and Culture Conditions}

The relevant features of bacterial strains, plasmids, and primers used in this experiment are listed in Table 1, Table S1, and Table S2.

Table 1. Bacterial strains used in the biosynthesis gene knockout study.

\begin{tabular}{lll}
\hline Strains & Relevant Features & References \\
\hline $\begin{array}{l}\text { Escherichia coli } \\
\text { NEB5 } \alpha\end{array}$ & Cloning host & NEB \\
JM101 & Cloning host $r e c A^{+}$ & {$[15]$} \\
\hline Lactococcus lactis (11) & & \\
NZ9000 & MG1363 pepN::nisRK, cloning host & {$[16]$} \\
$\Delta m e n A$ & NZ9000 menA deficient by lox72 replacement & This study \\
$\Delta m e n B$ & NZ9000 menB deficient by lox72 replacement & This study \\
$\Delta m e n E$ & NZ9000 menE deficient by lox72 replacement & This study \\
$\Delta m e n G$ & NZ9000 menG deficient by lox72 replacement & This study \\
\hline
\end{tabular}

L. lactis subsp. cremoris NZ9000 was grown at $30^{\circ} \mathrm{C}$ in M17 medium (Sigma-Aldrich, St. Louis, MO, USA) supplemented with $0.5 \%(w / v)$ glucose (GM17 broth) under anaerobic conditions (no agitation). Lactipl. plantarum WCFS1 and Lent. buchneri DSM 20057 were grown in MRS-medium (Roth) at $37^{\circ} \mathrm{C}$ overnight under anaerobic conditions. Escherichia coli NEB5 $\alpha$ and Escherichia coli JM101 were used as intermediate cloning host and were grown in LB broth at $37^{\circ} \mathrm{C}$ with agitation at $150 \mathrm{rpm}$. Solid media contained $1.5 \%$ agar. Antibiotics were used for $\mathrm{LAB}$ at final concentrations of $10 \mu \mathrm{g} / \mathrm{mL}$ of chloramphenicol (cm) and $10 \mu \mathrm{g} / \mathrm{mL}$ or $30 \mu \mathrm{g} / \mathrm{mL}$ (for replica plating) of erythromycin (ery). For E. coli, the concentrations were $10 \mu \mathrm{g} / \mathrm{mL}(\mathrm{Cm})$ and $250 \mu \mathrm{g} / \mathrm{mL}$ (ery), respectively.

Cultivation to assess aerobic growth was performed in baffled shake flasks filled to maximum $20 \%$ capacity with MRS broth at an agitation of $150 \mathrm{rpm}$. The growth medium was supplemented where indicated with menaquinone-4 (vitamin K2) (Sigma-Aldrich) at a final concentration of $20 \mathrm{ng} / \mathrm{mL}$ [1] or $1 \mu \mathrm{g} / \mathrm{mL}$ [6] and/or heme (Sigma-Aldrich) at a final concentration of $2 \mu \mathrm{g} / \mathrm{mL}$. Menaquinone- 4 was prepared as a stock solution at $2 \mathrm{mg} / \mathrm{mL}$ in ethanol, and heme was prepared as stock solution at $1 \mathrm{mg} / \mathrm{mL}$ in $0.05 \mathrm{M} \mathrm{NaOH}$. Stock solutions were filtered using $0.2 \mu \mathrm{m}$ sterile filters. As a control, an equivalent volume of ethanol or $0.05 \mathrm{M} \mathrm{NaOH}$ was added to non-supplemented media. Samples were taken after $24 \mathrm{~h}$ of growth for biomass $\left(\mathrm{OD}_{600}\right)$ and acidification $(\mathrm{pH})$ measurement. Growth and $\mathrm{pH}$ 
of induced and non-induced samples or with and without menaquinone supplementation samples were compared.

\subsection{Knock-Out Vector Constructions}

The construction of pNZ5319- $\Delta m e n A, \Delta m e n B, \Delta m e n E$, and $\Delta m e n G$ knock-out vectors was carried out by standard cloning procedures using restriction digestion and ligation [17]. The upstream and downstream fragments $(1.0 \mathrm{~kb}$ each) of the target genes $(m e n A$, menB, $m e n E$, men $G$ ) were amplified from L. lactis NZ9000 chromosomal DNA using primer combinations (Table S2) and ligated into the compatible restriction sites of pNZ5319 upstream of lox66 and downstream of lox71, respectively [17], and transformed into E. coli NEB5 $\alpha$ competent cells. The knockout constructs were verified by colony PCR and sequencing.

\subsection{L. lactis NZ9000 Gene Replacements}

The construction of the menA, men $B$, menE, and men $G$ deletion strains was done using the Cre-loxP system (Figure 1). The pNZ5319- $\Delta m e n A, \Delta m e n B, \Delta m e n E$, or $\Delta m e n G$ plasmids were transformed into L. lactis NZ9000 competent cells $[18,19]$ and selected for a chloramphenicol resistant and erythromycin sensitive phenotype, indicating double crossover at the homologous regions upstream and downstream of the lox66-P32-cm-lox71 cassette and loss of the plasmid backbone carrying the erythromycin resistance gene. The correct integration of the lox66-P32-cm-lox71 cassette and the absence of the coding sequences of menA, menB, menE, or $m e n G$ and ery were confirmed with primers, as listed in Table S2.

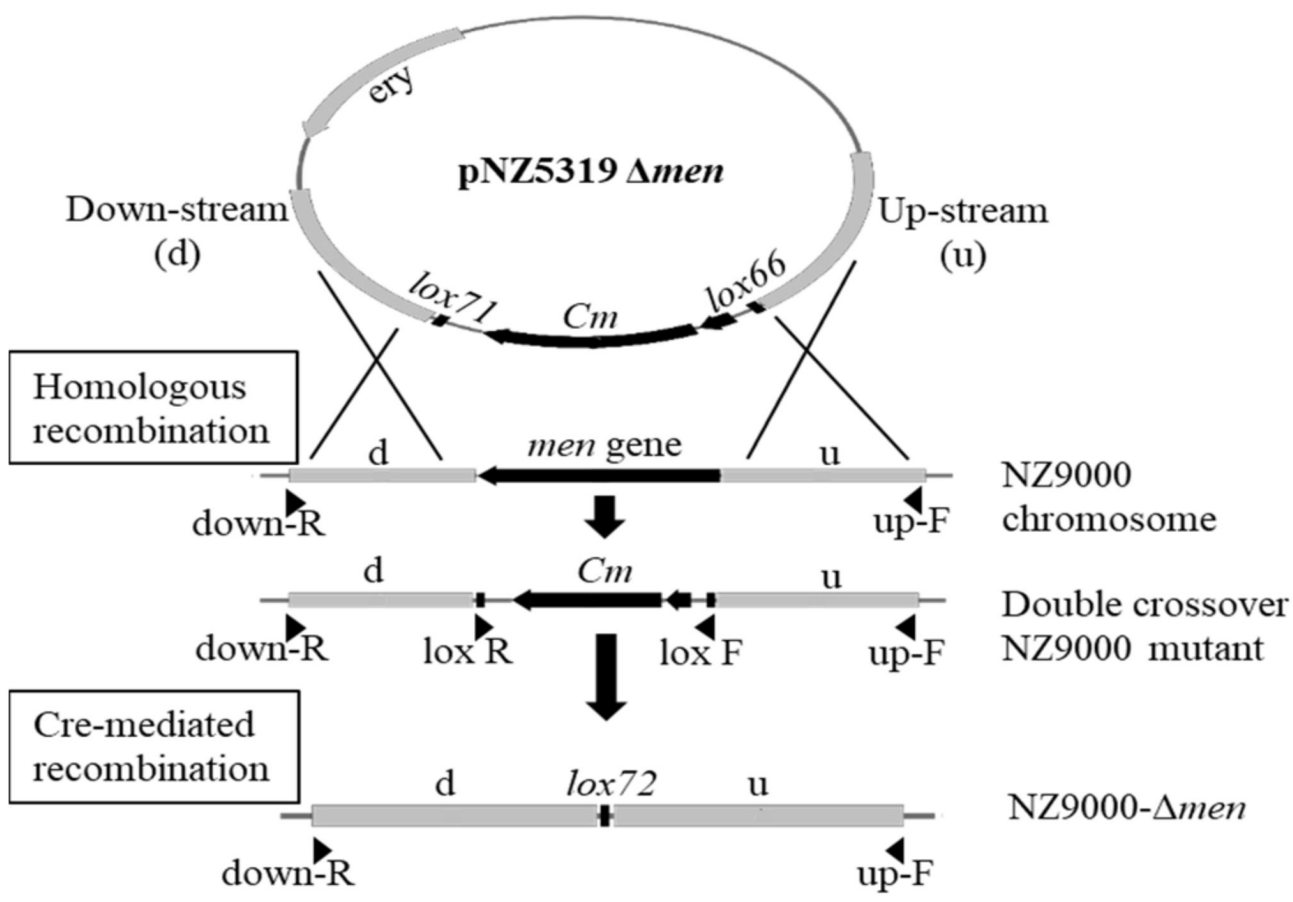

Figure 1. Construction of double-crossover men-gene replacement strains of L. lactis NZ9000 and subsequent Cre-lox-mediated selectable marker removal result in the L. lactis deletion strains (NZ9000$\Delta$ men). After transformation with either of the pNZ5319 knockout constructs, double crossover events result in the replacement of the target gene (men: $m e n A, \operatorname{men} B, \operatorname{men} E$, or $m e n G$ ) by the lox66P32-cm-lox71 cassette. The cm-cassette is later removed by Cre-mediated recombination, resulting in non-functional lox72 sites.

The antibiotic selection marker cassette (lox66-P32-cm-lox71) in the chromosomes of the knockout strains of L. lactis NZ9000 was excised using a transient Cre recombinase expression plasmid (pNZ5348) [17]. A total of 4-6 $\mu \mathrm{g}$ of pNZ5348 was transformed into the double crossover strains, and ery ${ }^{\mathrm{r}}$ colonies were picked and tested for Cre-mediated 
recombination, using primers spanning from upstream to downstream of the recombination locus (Table S2, Figure 1). The pNZ5348 plasmid was cured from the strains by growth without erythromycin selection pressure for about 10 generations, then 100-300 colonies were picked into microtiter plates with GM17 and tested for an ery ${ }^{\mathrm{s}}$ phenotype, indicating loss of the plasmid pNZ5348 [20]. Knockout genotypes were confirmed by sequencing (Microsynth, Balgach, Switzerland) using primers upstream and downstream of the respective loci as mentioned above.

\subsection{Construction of Expression Vectors for Menaquinone Biosynthesis Genes}

The nucleotide sequences coding for menA1, menA2, menA3, menG1, and menG2 genes from Lactipl. plantarum WCFS1 and menA, menB, menE, and men $G$ genes from Lent. buchneri DSM 20057 were amplified using appropriate primers (Table S3) and ligated into the nisininducible expression vector pNZ8150. Ligation mixtures were transformed into $E$. coli JM101 $(r e c A+)$ competent cells and verified by sequencing using primer pnz8150F and pnz8150R (Table S3). Plasmids for the expression of the homologous L. lactis NZ9000 genes $m e n A$, men $B$, menE, and men $G$ as controls were constructed analogously.

The L. lactis NZ9000 menaquinone biosynthesis-deficient strains ( $\triangle m e n A, \triangle m e n B$, $\Delta m e n E$, or $\Delta m e n G$ ) (Table 1) were transformed with the appropriate expression vector for the respective menaquinone biosynthesis gene (Table S4).

\subsection{Complementation of Deleted Menaquinone Biosynthesis Genes and Menaquinone Extraction}

The resulting strains (Table S5) were investigated for menaquinone formation. The transformant strains were cultivated following the manufacturer's protocol for the NICE Expression System for L. lactis. Overnight pre-cultures were diluted 1:100 into $500 \mathrm{~mL}$ fresh GM17 broth, grown to an optical density $\mathrm{OD}_{600}=0.4$, induced with $1 \mathrm{ng} / \mathrm{mL}$ nisin, and incubated further at $30^{\circ} \mathrm{C}$ for $24 \mathrm{~h}$ [1]. Cells were harvested by centrifugation at $5000 \times \mathrm{g}$ for $15 \mathrm{~min}$, washed twice with 1 volume potassium phosphate buffer (PPB; $\mathrm{pH}$ 6.0), and stored at $-20{ }^{\circ} \mathrm{C}$ until used for analysis.

Menaquinone extraction was performed in dark containers to avoid light-dependent degradation. A total of $1 \mathrm{~g}$ of cell biomass was transferred to an amber glass bottle and suspended into $1.5 \mathrm{~mL}$ PPB, $6.0 \mathrm{~mL}$ of methanol/acetone (1:1 $(v / v))$ [21] was added, and the suspension was vigorously agitated on an orbital shaker at $250 \mathrm{rpm}$ for $30 \mathrm{~min}$ at room temperature. Then, $2 \mathrm{~mL}$ of petroleum ether was added, and the mixture was again agitated for $10 \mathrm{~min}$ at $250 \mathrm{rpm}$. Following phase separation by 1 min centrifugation $\left(2800 \times g\right.$ at $\left.15^{\circ} \mathrm{C}\right)$, the upper layer was removed. The lower layer was re-extracted with $2 \mathrm{~mL}$ petroleum ether, the upper layer was again removed, and the two combined lower fractions were evaporated under nitrogen gas at room temperature. The dried residues containing menaquinone were dissolved in $10 \mu \mathrm{L}$ ethanol [1,22] for analysis.

\subsection{Thin-Layer Chromatography (TLC)}

The obtained extracts were analyzed using TLC, as described previously [23], with some modifications on Merck Kieselgel 60 F254 plates (Merck, Darmstadt, Germany). Hexane-diethyl ether (85:15) was used as the solvent system in the saturated chamber. The plates were dried and examined under UV light (254-365 nm), and purified menaquinone-4 (Sigma-Aldrich) was used as standard.

\subsection{Growth Profile Analysis}

Parent strains with disrupted biosynthesis genes were compared with transformant strains expressing the respective complementing gene from Lactipl. plantarum WCFS1 and Lent. buchneri DSM 20057 or L. lactis NZ9000 as control. Cultivation and induction were performed in aerobic condition as described above, and samples were taken for $\mathrm{pH}$ measurement and $\mathrm{OD}_{600}$ in three-hour intervals. 


\subsection{Construction of Expression Vectors for Menaquinone Biosynthesis}

For expression of menaquinone biosynthesis genes in Lactipl. plantarum WCFS1, the vector pSIP409 was used. An internal BsaI site was eliminated using site-directed mutagenesis [24] with the primers pSIP BsaI KO F and pSIP BsaI KO R (Table S3). The vector backbone was amplified from the modified pSIP409 (pSIP409 BsaI) with the primers pSIP409 $\mathrm{F}$ and pSIP409 R with BsaI restriction sites and complementary overhangs (Table S3). Menaquinone biosynthesis genes were amplified from the genome of L. lactis NZ9000 with primers as listed in Table S3, containing $5^{\prime}$ flanking bases, a BsaI restriction site, and a four-base overhang. A second promoter $\left(\mathrm{P}_{\text {sppQ_}} 2\right)$ fragment was amplified from pSIP409 as above with primers PsppQ F and PsppQ R.

Golden Gate Assembly was used to assemble the multiple DNA fragments and vector backbones in the form of synthetic operons encoding all six genes, with and without a second inducible promoter (PsppQ_2) inserted between the third and fourth genes. Oligonucleotide primer sequences are in Supplementary Material Table S6.

The assembly reactions were set up following the instruction manual of NEB Golden Gate Assembly Kit (New England BioLabs, Ipswich, MA, USA) and resulting in pSIP_lpMK_2 and pSIP_lpMK_1 (Table 2). The constructs with the expected size were confirmed by sequencing (Microsynth, Balgach, Switzerland) before being transformed into Lactipl. plantarum-competent cells.

Table 2. Plasmids used and menaquinone expression plasmid constructs for two Lactobacillus strains.

\begin{tabular}{|c|c|c|}
\hline Plasmids & Relevant Features & References \\
\hline pSIP409gusA & $\begin{array}{l}\text { spp-based expression vector, PSIP } 401 \text { derivative, gus } A \\
\text { controlled by } \mathrm{P}_{\text {spp } Q}\left(\mathrm{P}_{\text {orf }}\right) \text {, sppKR expression driven by eryB } \\
\text { read through }\end{array}$ & [25] \\
\hline pSIP409 BsaI & ery, PSIP401 derivative with removal of $B s a \mathrm{I}$ restriction site & This study \\
\hline pSIP_lpMK_2 & $\begin{array}{l}\text { ery, PSIP } 401 \Delta B s a \mathrm{I} \text { derivative, menaquinone biosynthesis } \\
\text { genes for Lactipl. plantarum controlled by two } \mathrm{P}_{\text {spp }} \mathrm{P}\end{array}$ & This study \\
\hline pSIP_lpMK_1 & $\begin{array}{l}\text { ery, PSIP } 401 \Delta B s a \text { I derivative, menaquinone biosynthesis } \\
\text { genes for Lactipl. plantarum controlled by one } \mathrm{P}_{s p p Q}\end{array}$ & This study \\
\hline
\end{tabular}

\subsection{Analysis of Aerobic Phenotype of Lactipl. plantarum variants}

The growth behavior of Lactobacillus variants and their wild type (control) was investigated under aerobic conditions, and overnight cultures were transferred into $100 \mathrm{~mL}$ MRS broth containing $5 \mu \mathrm{g} / \mathrm{mL}$ ery supplemented with $2 \mu \mathrm{g} / \mathrm{mL}$ heme in $500 \mathrm{~mL}$ baffled flasks, and were incubated at $37^{\circ} \mathrm{C}, 150 \mathrm{rpm}$ agitation speed. For the strains carrying an inducible plasmid, $25 \mathrm{ng} / \mathrm{mL}$ of SppIP was added at $\mathrm{OD}_{600}=0.3$, and sterile water was added to the controls and strains carrying the plasmid with the constitutive promoters. The $\mathrm{OD}_{600}$ and $\mathrm{pH}$ of the supernatant were measured at $0 \mathrm{~h}$ and $24 \mathrm{~h}$ incubation. Growth and $\mathrm{pH}$ of induced and non-induced clones were compared.

\section{Results}

\subsection{Construction of Menaquinone Knockout Vectors}

The knockout vectors were constructed using pNZ5319, which contains the ery antibiotic resistance marker as well as the lox66-P32-cm-lox71 cassette. This cassette was flanked with upstream and downstream sequences of the genes encoding the target MK biosynthesis genes (men $A$, men $B$, menE, or $m e n G$, respectively) to provide homologous recombination sites. $\mathrm{Cm}^{\mathrm{r}}$ colonies were verified for correct construction before transformation into L. lactis. Around $80 \%$ of the clones showed double crossover integration with replacement of the biosynthesis genes. Correct integration of the lox66-P32-cm-lox71 cassette and absence of $m e n A, m e n B, m e n G$, and $m e n E$ were confirmed by PCR as shown in Figure S1: men $A$, menB, $m e n E$, and $m e n G(906,843,1356$, and $741 \mathrm{bp}$, respectively) were replaced by the $1038 \mathrm{bp}$ of lox66-P32-cm-lox71 cassette. Representative strains were verified by sequencing before the next step was performed. 
Cre-mediated recombination was performed for the removal of P32 and the antibiotic resistance gene $(\mathrm{cm})$ from the L. lactis genome using a plasmid carrying the Cre recombinase gene (pNZ5348) [17]. Ery $^{\mathrm{r}}$ colonies containing pNZ5348 were checked for lox66/lox71 mediated recombination and excision of the marker cassette by a $\mathrm{cm}^{\mathrm{s}}$ phenotype and by verifying the loss of the 1038 bp-cassette (A-3, B-3, E-3, and G-3) (Figure S1). The presence of the non-functional lox72 site [17] resulting from lox66/lox71 recombination was confirmed by sequencing. The transient Cre expression vector (pNZ5348) was then cured through cultivation for 10 generations without erythromycin. About 5\% showed the ery ${ }^{\mathrm{s}}$ phenotype under nonselective conditions. The L. lactis $\Delta m e n A$, L. lactis $\Delta m e n B, L$. lactis $\Delta m e n E$, and L. lactis $\Delta m e n G$ knockout strains were used for the functional verification of the extant menaquinone biosynthesis genes from Lactipl. plantarum WCFS1 and Lent. buchneri DSM 20057.

\subsection{Expression of Menaquinone Genes from Lactipl. plantarum WCFS1}

The functionality of the menaquinone biosynthesis genes from Lactipl. plantarum WCFS1 and Lent. buchneri DSM 20057 was tested by analysis of menaquinone production and of growth profiles. The study of menaquinone production was conducted under anaerobic conditions, which resulted in a twofold yield of menaquinone production in $L$. lactis MG 1363 [1].

Menaquinone was extracted from all strains using solvent extraction and detected in TLC using menaquinone with four isoprenoid residues (MK-4) and a retardation factor $\left(R_{f}\right)$ of 0.29 as standard. Six of nine engineered strains, namely, those harboring lpmenA1, Ipmen G1, Ipmen G2, IbmenA, lbmenB, and lbmen G as well as L. lactis NZ9000 wild type (WT) showed bands representing menaquinone (Figure 2). The menaquinone band was absent in the extracts from all knockout strains (L. lactis $\Delta m e n A$, L. lactis $\Delta m e n B$, L. lactis $\Delta m e n E$, and L. lactis $\Delta m e n G)$. This confirms the successful abolishment of menaquinone biosynthesis by knocking out men $A$, men $B$, menE, or $m e n G$, as well the absence in L. lactis of orthologs of the men genes or of an alternative menaquinone biosynthetic pathway, as was reported for Helicobacter and Chlamydia strains [26].

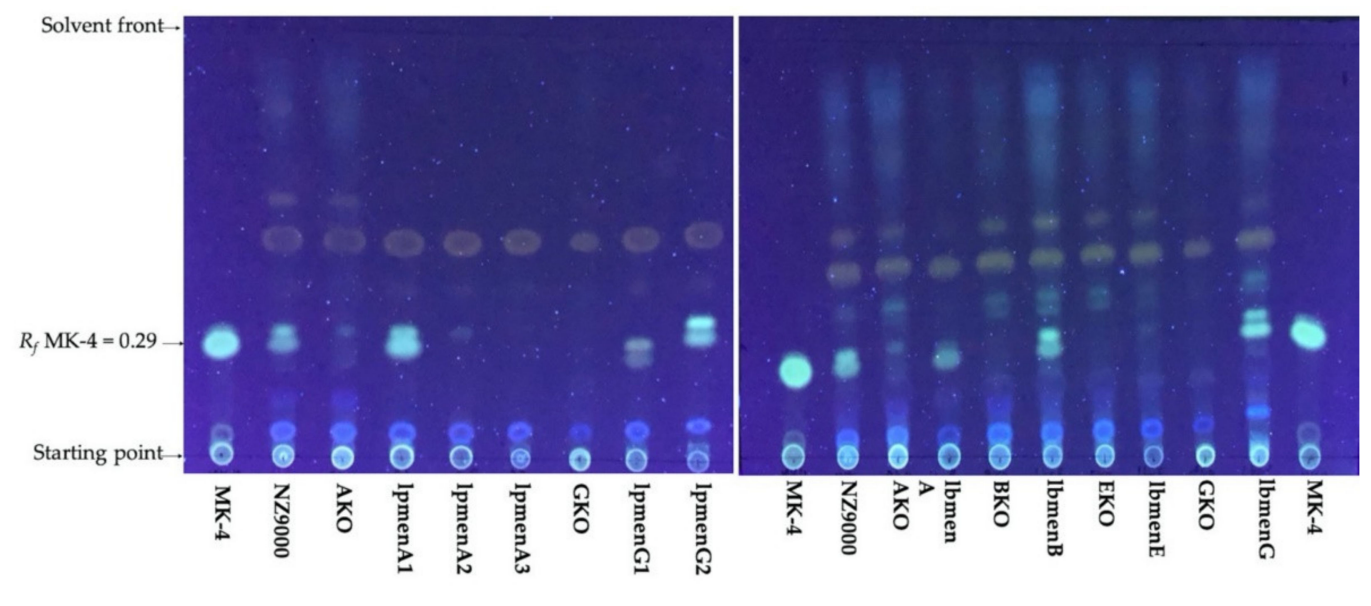

(a)

(b)

Figure 2. Menaquinone detection on TLC of the menaquinone extracts from L. lactis NZ9000; its deficient strains $\triangle m e n A(\mathrm{AKO}), \triangle m e n B(\mathrm{BKO}), \Delta m e n E(\mathrm{EKO})$, and $\triangle m e n G(\mathrm{GKO})$; and the engineered strains with complementing biosynthesis genes from (a) Lactipl. plantarum WCFS1 (lpmenA1, lpmenA2, IpmenA3, IpmenG1, lpmenG2) and (b) Lent. buchneri DSM 20057 (lbmenA, lbmenB, lbmenE, lbmenG). Menaquinone with four isoprenoid residues was used as standard (MK-4).

The menaquinone extract from the WT strain appeared as two nearly comigrating bands with $R_{f}$ values of 0.29 and 0.32 on TLC under UV detection. The same profile was detected in the menaquinone extracts from the strains carrying lpmenA1, IpmenG1, and lpmen G2; the extant menaquinone biosynthesis genes from Lactipl. plantarum WCFS1 
(Figure 2a); and the strains carrying the biosynthesis genes $\operatorname{lbmen} A, \operatorname{lbmenB}$, and $\operatorname{lbmen} G$ from Lent. buchneri DSM 20057 (Figure 2b). The different $R_{f}$ values for MK-4 $\left(R_{f}=0.29\right)$ and the higher band $\left(R_{f}=0.32\right)$ could be due to the production of menaquinone in varying side chain lengths (isoprenoid residues) from MK-2 to MK-10 of L. lactis $[1,27,28]$ or a detection artefact. In anaerobic conditions, L. lactis NZ9000 produces two dominant menaquinone variants (MK-3 and MK-9) [1], which are obviously seen in TLC as multiple menaquinone spots in the extracted samples (Figure 2). The $R_{f}$ of menaquinone homologues are readily separated in TLC [29-31] if the difference amounts to more than three isoprene units [30].

In contrast, no menaquinone could be detected in extracts of the strains expressing IpmenA2, IpmenA3, and lbmenE (Figure 2).

The menaquinone extracts from $L$. lactis NZ9000 and its menaquinone deficient strains $\triangle m e n B(\mathrm{BKO}), \Delta m e n E(\mathrm{EKO})$, and $\triangle m e n G(\mathrm{GKO})$ were checked for MK-6, which was found to be absent in these strains, but appeared in the WT sample (Figure S2), confirming the successful knockout of menaquinone biosynthesis in these strains.

\subsection{Growth Profile Analysis}

The growth profiles of L. lactis NZ9000 (WT) and $\Delta m e n G$ showed a high cell density $\left(\mathrm{OD}_{600}\right.$ about 5.8), whereas the L. lactis men $A-$, menB-, and menE-deficient strains showed an $\mathrm{OD}_{600}$ of about 4.0 under aerobic cultivation conditions with heme supplementation (Figure 3a). Interestingly, among the knockout strains, L. lactis $\Delta m e n G$ showed a cell density that was comparable to the wild type (Figure 3a). The men G gene encodes demethylmenaquinone methyltransferase (MenG), which adds a methyl group to the aromatic ring of demethylmenaquinone (DMK) and is the final step of menaquinone biosynthesis [32,33].

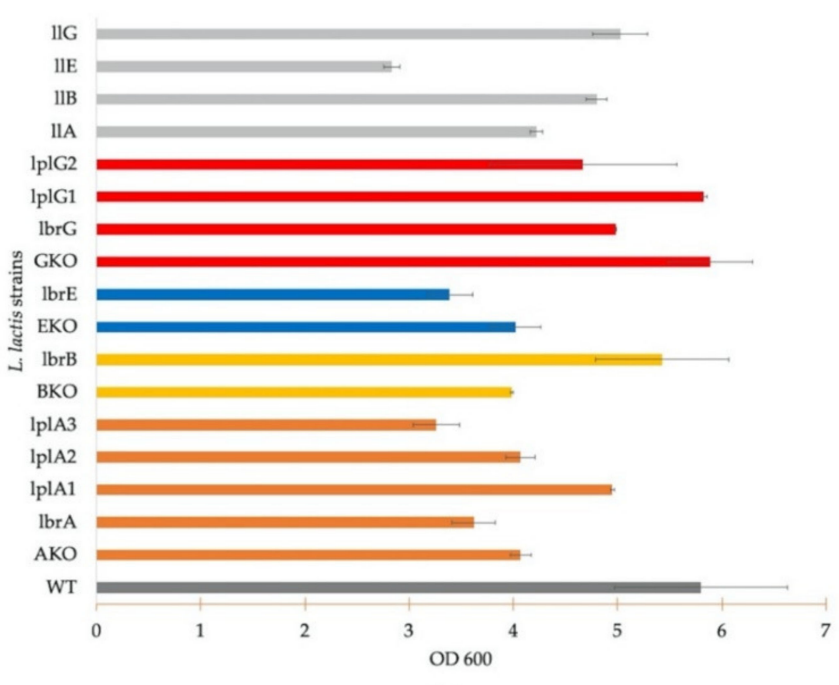

(a)

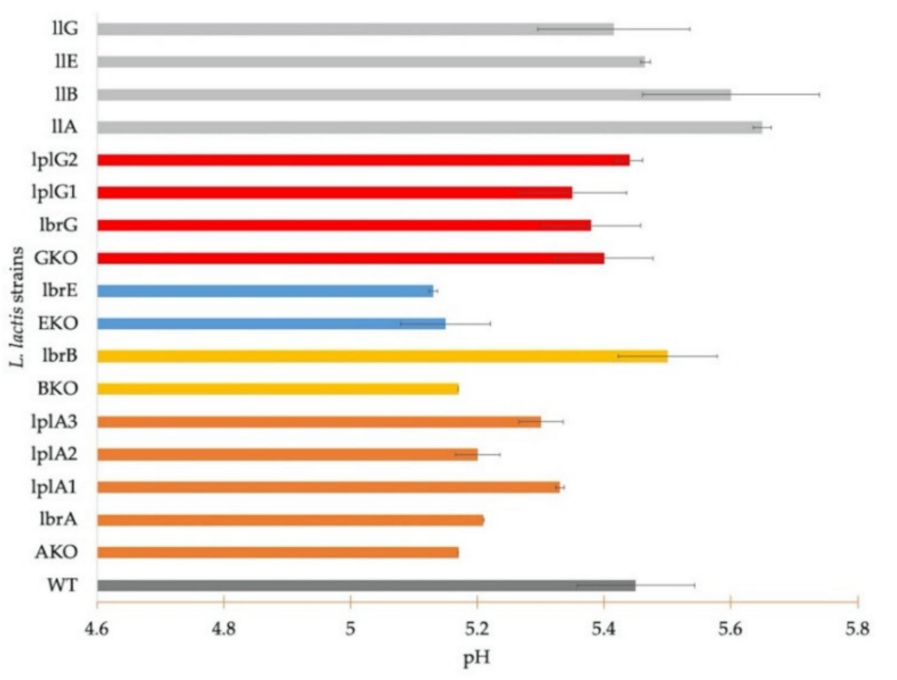

(b)

Figure 3. Growth (a) and $\mathrm{pH}$ profile (at $24 \mathrm{~h}$ incubation) (b) of L. lactis NZ9000 (WT), its menaquinone deficient strains $(\Delta m e n A, \Delta m e n B, \Delta m e n E, \Delta m e n G)$, L. lactis engineered strains carrying (lbmenA, lpmenA1, lpmenA2, lpmenA3, lbmenB, lbmenE, lbmen $G$, Ipmen G1, Ipmen G2), and engineered deficient strains complemented by homologous genes (llmenA, llmenB, llmenE, llmenG). A total of $300 \mathrm{~mL}$ of GM17 medium supplemented with heme $(2 \mu \mathrm{g} / \mathrm{mL})$ was used, and $1 \mathrm{ng} / \mathrm{mL}$ of nisin was added as inducer at $\mathrm{OD}_{600}=0.4$. Growth curves are presented in Supplementary Materials Figures S3-S5.

The functional verification of the menA genes from Lactipl. plantarum WCFS1 and Lent. buchneri DSM 20057 is shown in Figure 3a. An increased cell density $\left(\mathrm{OD}_{600}\right)$ was detected in the strain expressing the menA1 gene from Lactipl. plantarum WCFS1 with a maximum $\mathrm{OD}_{600}$ of 4.9. L. lactis $\triangle m e n A$, and the strain expressing lpmen $A 2$ showed a maximum $\mathrm{OD}_{600}$ of only 4.0, and lower growth was detected in the strains expressing lbmenA and lpmenA3 with $\mathrm{OD}_{600}$ of 3.6 and 3.2, respectively (Figure 3a). The complementation of L. lactis $\triangle m e n B$ by expression of lbmenB from Lent. buchneri DSM 20057 exhibited a maximum $\mathrm{OD}_{600}$ of 5.0 at $24 \mathrm{~h}$ incubation compared to an $\mathrm{OD}_{600}$ of $4.0 \mathrm{in}$ L. lactis $\Delta m e n B$. In contrast, L. lactis 
$\triangle m e n E$ reached an $\mathrm{OD}_{600}=4.0$, whereas the strain expressing $l b m e n E$ showed an $\mathrm{OD}_{600}$ of 3.4 after $24 \mathrm{~h}$ incubation (Figure $3 \mathrm{a}$ ).

The comparison of the growth profile between L. lactis $\triangle m e n G$ and its derivative strains expressing lbmen G, lpmen G1, or lpmenG2 gene showed a high growth phenotype during $24 \mathrm{~h}$ incubation for all strains. The highest $\mathrm{OD}_{600}$ at $24 \mathrm{~h}$ was observed in L. lactis $\Delta m e n G$ and the strain harboring lpmen $G 1$, followed by the strains carrying lpmen $G 2$ and lbmen $G$, with maximum $\mathrm{OD}_{600}$ values of 5.8, 5.8, 5.3, and 5.1, respectively.

The respiratory metabolism in L. lactis not only promotes biomass formation but also results in decreased lactic acid production [1]; thus, the $\mathrm{pH}$ of the cultures was monitored. The reduction of $\mathrm{pH}$ during growth of L. lactis NZ9000 and its men-deficient derivative strains is shown in Figure 3b. A higher $\mathrm{pH}$ of about 5.4 was observed in L. lactis NZ9000 and L. lactis $\triangle m e n G$ strains after $24 \mathrm{~h}$. A lower $\mathrm{pH}$ was observed in the $\triangle m e n A, \Delta m e n B$, and $\triangle m e n E$ strains. L. lactis $\Delta m e n G$, where only the last gene in the menaquinone biosynthesis pathway is knocked out, has uninhibited high growth and reduced acid production under aerobic conditions (Figure 3).

The $\mathrm{pH}$ monitoring during growth of L. lactis $\triangle m e n A$ and the complementation strains also verifies functionality of lpmenA1 from Lactipl. plantarum WCFS1. L. lactis lpmenA3 showed a $\mathrm{pH}$ as high as L. lactis lpmenA1 (5.3) but at lower growth. L. lactis lbmenA and lpmen $A 2$ showed a low $\mathrm{pH}$ comparable to the deficient strain L. lactis $\triangle m e n A$. L. lactis IbmenA showed a faint menaquinone band on TLC (Figure 2), but growth and $\mathrm{pH}$ profile were not restored to (near) WT levels.

The monitored $\mathrm{pH}$ curves show that lbmen $\mathrm{B}$ restored the respective growth phenotype, with a $\mathrm{pH}$ at $24 \mathrm{~h}$ of 5.6. The gene lbmenE was not able to restore menaquinone production, as shown by growth (Figure 3) and menaquinone detection on TLC (Figure 2).

The knockout mutations were also complemented by expression of the homologous menaquinone biosynthesis genes (llmenA, llmenB, llmenE, llmenG) from L. lactis NZ9000 in order to determine potential differences between homologous and heterologous genes/enzymes as well as the metabolic load of plasmid maintenance to cell growth. The knockout strains expressing $l$ lmen $A$ and $l$ lmen $B$ showed higher growth than the deficient strains at an $\mathrm{OD}_{600}$ of 4.2 and 4.8 , respectively. L. lactis llmen $\mathrm{G}$ exhibited slightly lower growth $\left(\mathrm{OD}_{600}=5.0\right)$ than L. lactis $\Delta m e n G\left(\mathrm{OD}_{600}=5.8\right)$, but the cell growth was comparable to other men $G$ expression strains (Figure 3). Lower biomass formation was observed in the L. lactis llmenE with the $\mathrm{OD}_{600}$ of 2.8, similar to L. lactis lbmenE, and both were lower than L. lactis $\triangle m e n E$.

The $\mathrm{pH}$ profile of all strains expressing homologous genes showed higher $\mathrm{pH}$ than the respective deficient strains ranging from $\mathrm{pH} 5.4$ to 5.6 (Figure $3 \mathrm{~b}$ ), except L. lactis lbmenE, where a higher final $\mathrm{pH}$ corresponded to low growth.

\subsection{Respiratory Phenotype of Lent. buchneri DSM 20057 and Lactipl. plantarum WCFS1 and Variant Strains}

Both Lent. buchneri and Lactipl. plantarum were cultivated under aerobic conditions with supplementation of both heme and menaquinone (Figure 4). In Lactipl. plantarum WCFS1, $\mathrm{OD}_{600}$ increased from 2.4 without heme and menaquinone supplementation to 4.5 (Figure 4a). In Lent. buchneri DSM 20057, OD $_{600}$ increased from 1.5 without supplementation to 3.4 when supplemented with heme and menaquinone (Figure $4 \mathrm{~b}$ ). The final $\mathrm{pH}$ after $24 \mathrm{~h}$ cultivation of Lactipl. plantarum was about 4.3 in all samples, with and without supplementation (Figure 4a). The final pH of Lent. buchneri DSM 20057 without exogenous heme and menaquinone was 4.9 ; with supplementation, the final $\mathrm{pH}$ was slightly lower at 4.5 (Figure $4 \mathrm{~b}$ ). Menaquinone was supplied at $20 \mathrm{ng} / \mathrm{mL}$ and $2 \mu \mathrm{g} / \mathrm{mL}$, but no concentration-dependent differences were observed in biomass formation or in final $\mathrm{pH}$ (Figure $4 a, b)$. 


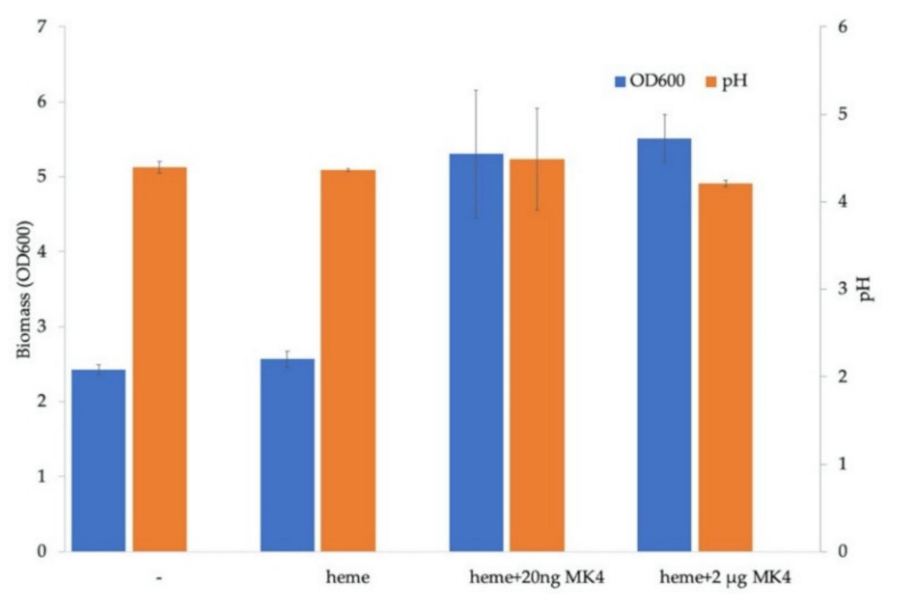

(a)

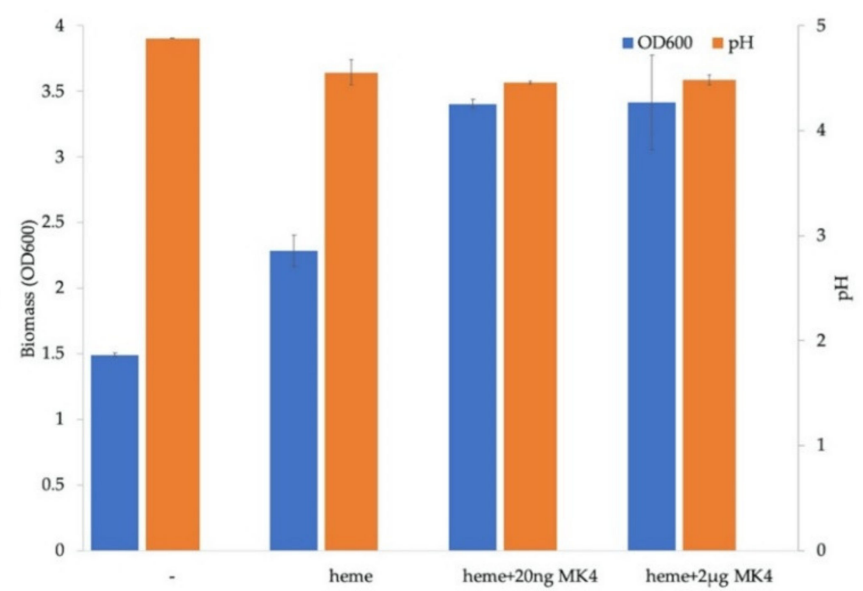

(b)

Figure 4. Lactipl. plantarum WCFS1 (a) and Lent. buchneri DSM 20057 (b) were grown aerobically for $24 \mathrm{~h}$ at $37^{\circ} \mathrm{C}$ in MRS medium without heme and menaquinone supplementation (-), with only heme supplementation (heme), and with heme and $20 \mathrm{ng} / \mathrm{mL}$ or $2 \mu \mathrm{g} / \mathrm{mL}$ menaquinone supplementation (heme + MK4). The blue bars represent the biomass formation $\left(\mathrm{OD}_{600}\right)$, and the orange bars represent the final $\mathrm{pH}$.

Lactipl. plantarum was transformed with an expression vector (pSIP_lpMK_1), which carried the six menaquinone biosynthesis genes controlled by one promoter. The resulting strain showed the same growth behavior under induced and non-induced conditions (Figure 5a), and identical levels of $\mathrm{pH}$ were measured in both samples. The expression vector pSIP_lpMK_2 carries the six menaquinone biosynthesis genes with an additional inducible promoter between the third and fourth gene. A Lactipl. plantarum strain carrying this construct showed higher biomass formation under aerobic conditions with heme supplementation upon induction of the biosynthesis genes. The $\mathrm{OD}_{600}$ of the sample without induction after $24 \mathrm{~h}$ cultivation was about 3.0, and the induced sample showed an $\mathrm{OD}_{600}$ of about 5.0 (Figure $5 \mathrm{~b}$ ). The control sample, where heme and menaquinone were added, gave an $\mathrm{OD}_{600}$ of 7.0. The final $\mathrm{pH}$ measurement revealed that all three samples had a $\mathrm{pH}$ around 4.1 (Figure $5 \mathrm{~b}$ ).

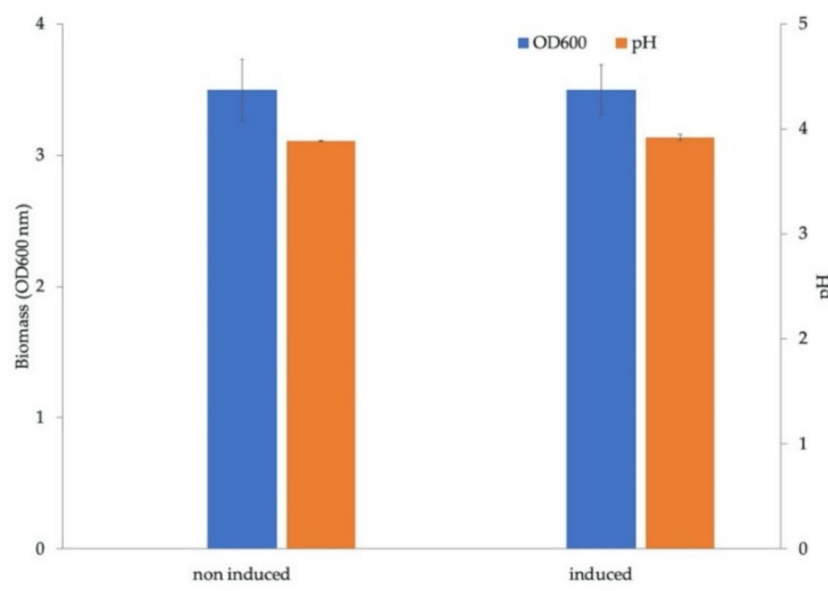

(a)

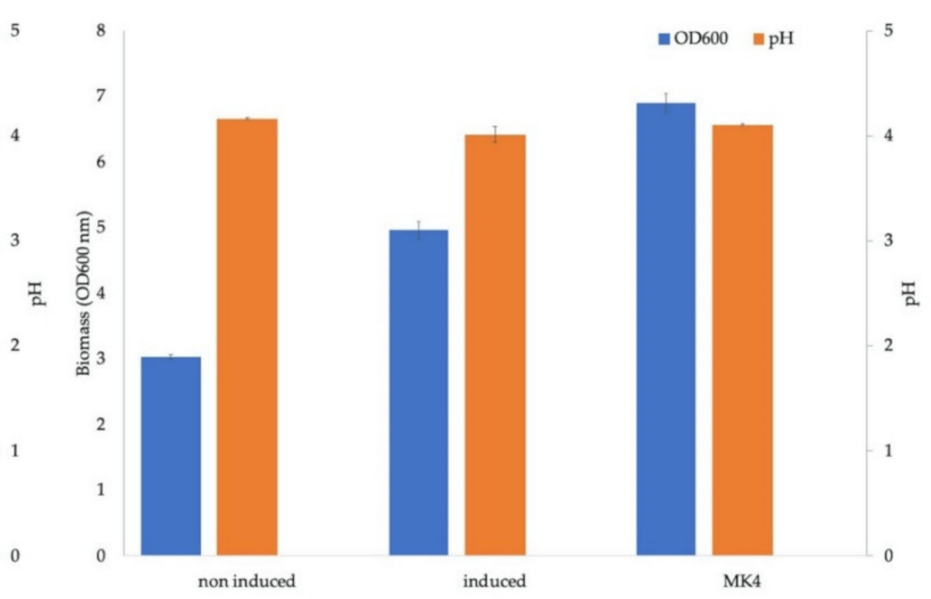

(b)

Figure 5. Cultivation of Lactipl. plantarum carrying the plasmids pSIP_lpMK_1 (a) and pSIP_lpMK_2 (b). The engineered strain was grown aerobically for $24 \mathrm{~h}$ at $37^{\circ} \mathrm{C}$ in MRS medium with IP (induced) and without IP (non-induced) as the inducer. The blue bars represent the biomass formation $\left(\mathrm{OD}_{600}\right)$, and the orange bars represent the final $\mathrm{pH}$. 


\section{Discussion}

To verify the functionality of the existing menaquinone biosynthesis genes from Lactipl. plantarum WCFS1 (menA, menG) and Lent. buchneri DSM 20057 (menA, menB, menE, $m e n G$ ), we constructed respective knock-out strains in L. lactis (which has a complete set of menaquinone biosynthesis genes) using the Cre-loxP system with selection marker removal by Cre recombinase [17]. Deletion of $m e n A, m e n B$, and $m e n E$ had the expected effect on the growth behavior of L. lactis NZ9000 due to incomplete menaquinone biosynthesis, i.e., higher biomass formation and reduced medium acidification associated with respiratory metabolism in aerobic cultivation was abolished. An exception was L. lactis NZ9000 $\Delta m e n G$, which showed cell densities and medium acidification comparable to the wild type L. lactis NZ9000 (Figure 3a). MenG encodes demethylmenaquinone methyltransferase, the enzyme catalyzing the final step of menaquinone biosynthesis: conversion of DMK to MK by addition of a methyl group to the aromatic ring of DMK $[28,29]$. E. faecalis only synthesizes DMK but has also shown respiratory growth upon medium supplementation with heme [33-36], and a Staphylococcus aureus $\Delta m e n G$ strain exhibited functional electron transport using DMK [27]. These observations suggest that DMK is functional as electron shuttle in the electron transport chain.

Expression of Lactipl. plantarum menA1 led to restoration of menaquinone biosynthesis and a growth behavior comparable to the wild type upon aerobic cultivation, i.e., higher biomass formation and reduced acidification. From this, we conclude that the extant menA1 gene still encodes a fully functional enzyme in Lactipl. plantarum. Expression of $m e n A 2$ or menA3 from Lactipl. plantarum in L. lactis $\triangle m e n A$ did not fully restore the growth phenotype or menaquinone production as analyzed by TLC. Thus, the respective genes, while appearing to be intact in the genome (i.e., there are no obvious larger deletions or insertions or mutations causing a frameshift), no longer encode functional enzymes due to the accumulation of non-functionalizing mutations. The strain expressing $m e n A$ from Lent. buchneri displayed menaquinone production in TLC, but markedly weaker than in the other, successfully complemented strains, and a respiration-associated growth phenotype could not be restored. The most likely explanation is that these genes have, in the absence of selective pressure on functionality, accumulated mutations that have not entirely abolished its function but compromised the catalytic activity of the enzyme, leading to production levels in the complementation strain that are, albeit detectable, insufficient for a functional electron transport chain.

$M e n E$ expression produced results (in all tests) almost undistinguishable from the knock-out strain, suggesting that the gene no longer encodes an intact enzyme. In this case, however, complementation with the homologous $l l m e n E$ was equally unsuccessful. Closer examination revealed that the design of the knock-out cassette is probably responsible for this: $m e n E$ is overlapping the immediately following $m e n C$ by four nucleotides, i.e., $\mathrm{TG}$ in the start codon and A in the second codon (ATA, Ile) of the menC coding region constitute the menE stop codon TGA. This was taken into account, and the disruption cassette was constructed using the intact men $C$ coding sequence as downstream homologous element for the integration of the marker cassette. Thus, integration of the construct via double crossover also removes the $m e n C$ ribosome binding site (RBS). Cre-recombinase-mediated excision of the cassette via the lox66/lox71 sites should move the menE RBS to a position upstream of the men $C$ start codon; however, the remaining lox 72 site increases the distance between RBS and start codon by more than $30 \mathrm{nts}$. This could affect translation of menC and lead to lowered enzyme titers of active MenC. If that is indeed the case, complementation of the menE knock-out will be unsuccessful because of insufficient MenC-activity, even if the complementing menE gene is functional. We did not determine MenC activity or quantify MenC in the knock-out or the complemented strain, and the complementation experiment with Lent. buchneri menE is therefore inconclusive. On the basis of our initial interpretation, that Lent. buchneri menE no longer encodes a functional enzyme, lbmenE was included in the expression constructs for pathway restoration. 
Deletion of L. lactis men G did not give a conclusive growth phenotype, as described above, and thus complementation by any of the genes encoding the demethylmenaquinone methyltransferase, menG1 and menG2 from Lactipl. plantarum, and menG from Lent. buchneri cannot be detected. TLC analysis of the respective strains, however, clearly shows restored menaquinone production in all the strains expressing either one of these three genes, indicating that all three genes encode functional enzymes.

TLC analysis of extracts of the various L. lactis strains generally gave spots with two slightly different $R_{f}$ values near the position of MK-4. Menaquinone occurs in side chain lengths (number of isoprenoid residues) from MK-2 to MK-10 in L. lactis $[1,27,28]$. Under anaerobic conditions, two dominant menaquinones, MK-3 and MK-9, are detected [1], which can be seen in TLC (Figure 2). Menaquinones are readily separated in TLC [29-31] if the difference is more than three isoprene units [30].

In reports on L. lactis, respiratory metabolism led to both higher biomass formation as well as lower acidification of the growth medium [1]. Under fermentation conditions, lactate dehydrogenase (LDH) produces lactate from pyruvate, concomitantly regenerating $\mathrm{NAD}^{+}$from NADH. Under aerobic conditions and heme supplementation, the encoding gene $l d h$ was downregulated, and the gene encoding pyruvate dehydogenase $(p d h)$ was upregulated [37]. This results in formation of acetate and acetoin production at the expense of lactate [7,38], leading to less pronounced acidification and higher final $\mathrm{pH}$, while maintaining $\mathrm{NADH}$ consumption $/ \mathrm{NAD}^{+}$regeneration through NADH oxidase [39]. In our results, we observed higher biomass formation upon respiratory metabolism, but not a lower final $\mathrm{pH}$, in both wild type strains (Lactipl. plantarum WCFS1 and Lent. buchneri DSM 20057), as well as the engineered Lactipl. plantarum strain. A possible explanation is that acetoin production is absent in Lactipl. plantarum, leading to (mostly) acetate production instead of lactate, which may result in the same final $\mathrm{pH}$. Besides that, doubt has been cast onto the rerouting of metabolism via PDH due to proteomic studies [40]. Investigation of the transcriptomic response to aerobic conditions, heme supplementation, and menaquinone biosynthesis will be part of future work.

Interestingly, supplementation with only heme led to a higher biomass formation in Lent. buchneri DSM 20057 in aerobic cultivation (Figure 4b), but lower than upon supplementation with heme and menaquinone. The genes for oxidases (pyruvate oxidase, lactate oxidase) are upregulated in aerobic conditions together with other genes [41] This can lead to an accumulation of hydrogen peroxide and free radicals, resulting in oxidative damage to cellular components [42]. Supplementation of heme under aerobic conditions induces the production of heme-dependent catalase and thus to degradation of hydrogen peroxide $[3,42,43]$ and alleviation of oxidative stress. This was also observed in L. rhamnosus in the presence of heme after expression of a gene encoding heme-dependent catalase (KatA) [44]. However, this effect was not observed under aerobic conditions in Lactipl. plantarum WCFS1 (Figure 4a), although increased expression of catalase under aerobiosis was shown in Lactipl. plantarum as well [45]. Lactipl. plantarum was shown to produce a Mn-dependent (pseudo)catalase $[42,43,46]$ that decomposes hydrogen peroxide under aerobic conditions without requiring heme, as well as another, $\mathrm{Mn}$ (II)-based and heme-independent stress resistance mechanism to detoxify superoxide [47], and it is not clear to what extent these different mechanisms contribute to oxidative stress response.

In a first trial at pathway reconstruction, we assembled the six menaquinone biosynthesis genes (each with its own RBS) into a polycistronic operon under control of a single promoter. On the basis of the observed growth behavior, we found that this did not result in respiratory metabolism. Reports in literature suggest that transcription of mRNAs beyond a certain length leads to a low ratio of full-length RNAs and consequently low yields of the protein(s) encoded by the gene(s) furthest downstream from the promoter [48]. A limit of four genes (of average length) transcribed from one promoter is suggested [49]. We conclude that the last or the two last genes in the construct (menC and menE) are transcribed only at low levels (i.e., that full-length mRNAs containing these two coding regions are rare), resulting in levels of functional enzyme that are too low to produce sufficient amounts 
of menaquinone. This can be remedied by positioning of a strong promoter upstream of every gene [50]. Since the required construct consists of six genes, assembly of these genes with six promoters was considered cumbersome and inefficient, whether by restriction and ligation or by Golden Gate Assembly. We therefore decided on an expression vector with two operons of three genes, each controlled by the same inducible promoter. The genes were placed in the same order as in the genome of L. lactis NZ9000, with menF, mend, and menH controlled by the first promoter, followed by the second promoter controlling the expression of menB, menE, and menC. Strains transformed with this construct could, upon induction of the two promoters controlling the menaquinone biosynthesis genes, produce higher biomass (Figure $5 b$ ), indicating a successful restoration of menaquinone biosynthesis and a complete respiratory chain.

Supplementary Materials: The following are available online at https://www.mdpi.com/article/ 10.3390/microorganisms9071476/s1, Figure S1: Diagnostic PCR of L. lactis NZ9000 menA (A-1), its gene replacement mutant menA:: lox66-P32-cm-lox71 (A-2), $\triangle$ menA (A-3); menB (B-1), menB:: lox66-P32-cm-lox71 (A-2), $\Delta$ menB (B-3); menE (E-1), menE:: lox66-P32-cm-lox71 (E-2), $\Delta$ menE (E-3); menG (G-1), menG:: lox66-P32-cm-lox71 (A-2), $\Delta$ menG (G-3); M is a 2 log DNA ladder, Figure S2: Base peak chromatogram of menaquinone extracts from L. lactis NZ9000 (WT) and its menaquinone deficient strains $\triangle$ menB (BKO), $\triangle$ menE (EKO), $\Delta$ menG (GKO) for MK-6, Figure S3: Growth profile analysis of (a) L. lactis NZ9000 (WT) and the knockout strains ( $\triangle \mathrm{menA}, \Delta \mathrm{menB}, \Delta \mathrm{menE}, \Delta \mathrm{menG}$ ), (b) L. lactis $\triangle$ menA and its engineered derivatives carrying lbmenA, lpmenA1, lpmenA2 and lpmenA3), (c) L. lactis $\triangle \mathrm{menB}$, L. lactis $\Delta \mathrm{menE}$ and the engineered derivatives (carrying lbmenB, lbmenE) and (d) L. lactis $\triangle \mathrm{menG}$ and its engineered derivatives carrying lbmenG, lpmenG1 and lpmenG2. $300 \mathrm{~mL}$ of GM17 medium supplemented with heme $(2 \mu \mathrm{g} / \mathrm{mL})$ were used, $1 \mathrm{ng} / \mathrm{mL}$ of nisin was added as an inducer at OD600 $=0.4$, Figure S4: $\mathrm{pH}$ profile of (a) L. lactis NZ9000 (WT) and its menaquinone deficient strains ( $\triangle \mathrm{menA}, \Delta \mathrm{menB}, \Delta \mathrm{menE}, \Delta \mathrm{menG}$ ), (b) L. lactis $\Delta \mathrm{menA}$ and its engineered strains (lbmenA, lpmenA1, lpmenA2, lpmenA3), (c) L. lactis $\Delta$ menB, L. lactis $\Delta$ menE and its engineered strains (lbmenB, lbmenE) and (d) L. lactis $\Delta$ menG and its engineered strains (lbmenG, lpmenG1, lpmenG2). $300 \mathrm{~mL}$ of GM17 medium supplemented with heme $(2 \mu \mathrm{g} / \mathrm{mL})$ was used, $1 \mathrm{ng} / \mathrm{mL}$ of nisin was added as inducer at OD600 $=0.4$, Figure S5: Growth profile (A) and pH analysis (B) of L. lactis NZ9000 (WT) and engineered deficient strains complemented by homologous genes (llmenA, llmenB, llmenE, llmenG). $300 \mathrm{~mL}$ of GM17 medium supplemented with heme $(2 \mu \mathrm{g} / \mathrm{mL})$ were used, $1 \mathrm{ng} / \mathrm{mL}$ of nisin was added as an inducer at OD600 $=0.4$, Table S1: The Cre-lox system plasmids and knockout plasmid constructs, Table S2: Sequence of oligonucleotide primers, Table S3: Primers used for the functional verification of menaquinone biosynthesis genes study, Table S4: Plasmids and menaquinone expression plasmid constructs, Table S5: Lactococcus lactis strains with menaquinone expression plasmid, Table S6: Primers used for the reconstitution of menaquinone biosynthesis pathway in Lactipl. plantarum and Lent. buchneri strains.

Author Contributions: Conceptualization, C.P.; methodology, N.W. and L.J.V.; validation, N.W., C.P. and D.H.; resources, C.P. and D.H.; writing—original draft preparation, N.W.; writing-review and editing, C.P.; supervision, C.P.; project administration, C.P.; funding acquisition, C.P. and D.H. All authors have read and agreed to the published version of the manuscript.

Funding: N.W. and L.J.V. are grateful for Ernst Mach-ASEA Uninet scholarships granted by the OeAD-Austrian Agency for International Cooperation in Education and Research and financed by the Austrian Federal Ministry of Education, Science and Research.

Institutional Review Board Statement: Not applicable.

Informed Consent Statement: Not applicable.

Acknowledgments: The authors thank Leander Sützl, Anh-Minh Tran (University of Natural Resources and Life Sciences, Vienna), and Mai-Lan Pham (Donau University Krems) for their help in experimental work and discussions.

Conflicts of Interest: The authors declare no conflict of interest. 


\section{References}

1. Brooijmans, R.; Smit, B.; Santos, F.; van Riel, J.; de Vos, W.M.; Hugenholtz, J. Heme and menaquinone induced electron transport in lactic acid bacteria. Microb. Cell Fact. 2009, 8, 1-11. [CrossRef] [PubMed]

2. Gaudu, P.; Vido, K.; Cesselin, B.; Kulakauskas, S.; Tremblay, J.; Rezaïki, L.; Lamberet, G.; Sourice, S.; Duwat, P.; Gruss, A. Respiration capacity and consequences in Lactococcus lactis. Antonie Van Leeuwenhoek 2002, 82, 263-269. [CrossRef] [PubMed]

3. Lechardeur, D.; Cesselin, B.N.D.; Fernandez, A.; Lamberet, G.; Garrigues, C.; Pedersen, M.; Gaudu, P.; Gruss, A. Using heme as an energy boost for lactic acid bacteria. Curr. Opin. Biotechnol. 2010, 22, 143-149. [CrossRef] [PubMed]

4. Zotta, T.; Ricciardi, A.; Ianniello, R.G.; Storti, L.V.; Glibota, N.A.; Parente, E. Aerobic and respirative growth of heterofermentative lactic acid bacteria: A screening study. Food Microbiol. 2018, 76, 117-127. [CrossRef]

5. Reale, A.; Ianniello, R.G.; Ciocia, F.; di Renzo, T.; Boscaino, F.; Ricciardi, A.; Coppola, R.; Parente, E.; Zotta, T.; McSweeney, P.L.H. Effect of respirative and catalase-positive Lactobacillus casei adjuncts on the production and quality of Cheddar-type cheese. Int. Dairy J. 2016, 63, 78-87. [CrossRef]

6. Reale, A.; di Renzo, T.; Zotta, T.; Preziuso, M.; Boscaino, F.; Ianniello, R.; Storti, L.V.; Tremonte, P.; Coppola, R. Effect of respirative cultures of Lactobacillus casei on model sourdough fermentation. LWT Food Sci. Technol. 2016, 73, 622-629. [CrossRef]

7. Pedersen, M.B.; Gaudu, P.; Lechardeur, D.; Petit, M.-A.; Gruss, A. Aerobic respiration metabolism in lactic acid bacteria and uses in biotechnology. Annu. Rev. Food Sci. Technol. 2012, 3, 37-58. [CrossRef]

8. Zotta, T.; Parente, E.; Ricciardi, A. Aerobic metabolism in the genus Lactobacillus: Impact on stress response and potential applications in the food industry. J. Appl. Microbiol. 2017, 122, 857-869. [CrossRef]

9. Kurosu, M.; Begari, E. Vitamin K2 in electron transport system: Are enzymes involved in vitamin K2 biosynthesis promising drug targets? Molecules 2010, 15, 1531-1553. [CrossRef]

10. Brooijmans, R. Electron Transport Chains of Lactic Acid Bacteria; Wageningen University: Wageningen, The Netherlands, 2008.

11. Cesselin, B.; Derré-Bobillot, A.; Fernandez, A.; Lamberet, G.; Lechardeur, D.; Yamamoto, Y.; Pedersen, M.B.; Garrigues, C.; Gaudu, P. Respiration, a strategy to avoid oxidative stress in Lactococcus lactis, is regulated by the heme status. Jpn. J. Lact. Acid Bact. 2010, 21, 10-15. [CrossRef]

12. Malarme, K.; Malarme, K.; Weissenbach, J.; Weissenbach, J.; Ehrlich, S.D.; Ehrlich, S.D.; Sorokin, A.; Sorokin, A. The complete genome sequence of the lactic acid bacterium Lactococcus lactis ssp. lactis IL1403. Genome Res. 2001, 11, 731-753. [CrossRef]

13. Wegmann, U.; Zomer, A.; Buist, G.; Shearman, C.; Canchaya, C.; Ventura, M.; Goesmann, A.; Gasson, M.J.; Kuipers, O.P.; van Sinderen, D.; et al. Complete genome sequence of the prototype lactic acid bacterium Lactococcus lactis subsp cremoris MG1363. J. Bacteriol. 2007, 189, 3256-3270. [CrossRef]

14. Brooijmans, R.; de Vos, W.M.; Hugenholtz, J. Lactobacillus plantarum WCFS1 electron transport chains. Appl. Environ. Microbiol. 2009, 75, 3580-3585. [CrossRef]

15. Sambrook, J.; Fritsch, F.E.; Maniatis, T. Molecular Cloning: A Laboratory Manual; Cold Spring Harbor Laboratory Press: Cold Spring Harbor, NY, USA, 1989.

16. Kuipers, O.P.; de Ruyter, P.G.G.; Kleerebezem, M.; de Vos, W.M. Quorum sensing-controlled gene expression in lactic acid bacteria. J. Biotechnol. 1998, 64, 15-21. [CrossRef]

17. Lambert, J.M.; Bongers, R.S.; Kleerebezem, M. Cre-lox-based system for multiple gene deletions and selectable-marker removal in Lactobacillus plantarum. Appl. Environ. Microbiol. 2007, 73, 1126-1135. [CrossRef]

18. Geertsma, E.R.; Poolman, B. High-throughput cloning and expression in Lactococcus lactis. Nat. Methods 2007, 4, 705-707. [CrossRef]

19. Holo, H.; Nes, I.F. High-frequency transformation, by electroporation, of Lactococcus lactis subsp cremoris grown with glycine in osmotically stabilized media. Appl. Environ. Microbiol. 1989, 55, 3119-3123. [CrossRef] [PubMed]

20. Nicoloff, H.; Hubert, J.C.; Bringel, F. In Lactobacillus plantarum, carbamoyl phosphate is synthesized by two carbamoyl-phosphate synthetases (CPS): Carbon dioxide differentiates the arginine-repressed from the pyrimidine-regulated CPS. J. Bacteriol. 2000, 182, 3416-3422. [CrossRef] [PubMed]

21. Wei, H.; Zhao, G.; Liu, H.; Wang, H.; Ni, W.; Wang, P.; Zheng, Z. A simple and efficient method for the extraction and separation of menaquinone homologs from wet biomass of Flavobacterium. Bioprocess Biosyst. Eng. 2018, 41, 107-113. [CrossRef]

22. Myers, J.M.; Myers, C.R. Role of the tetraheme cytochrome CymA in anaerobic electron transport in cells of Shewanella putrefaciens MR-1 with normal levels of menaquinone. J. Bacteriol. 2000, 182, 67-75. [CrossRef]

23. Morishita, T.; Tamura, N.; Makino, T.; Kudo, S. Production of menaquinones by lactic acid bacteria. J. Dairy Sci. 1999, 82, 1897-1903. [CrossRef]

24. Zheng, L.; Baumann, U.; Reymond, J.-L. An efficient one-step site-directed and site-saturation mutagenesis protocol. Nucleic Acids Res. 2004, 32, e115. [CrossRef]

25. Sørvig, E.; Mathiesen, G.; Naterstad, K.; Eijsink, V.G.H.; Axelsson, L. High-level, inducible gene expression in Lactobacillus sakei and Lactobacillus plantarum using versatile expression vectors. Microbiology 2005, 151, 2439-2449. [CrossRef]

26. Dairi, T. An alternative menaquinone biosynthetic pathway operating in microorganisms: An attractive target for drug discovery to pathogenic Helicobacter and Chlamydia strains. J. Antibiot. 2009, 62, 347-352. [CrossRef] [PubMed]

27. Wakeman, C.A.; Hammer, N.D.; Stauff, D.L.; Attia, A.S.; Anzaldi, L.L.; Dikalov, S.I.; Calcutt, M.W.; Skaar, E.P. Menaquinone biosynthesis potentiates haem toxicity in Staphylococcus aureus. Mol. Microbiol. 2012, 86, 1376-1392. [CrossRef] [PubMed] 
28. Rezaiki, L.; Lamberet, G.; Derré, A.; Gruss, A.; Gaudu, P. Lactococcus lactis produces short-chain quinones that cross-feed Group B Streptococcus to activate respiration growth. Mol. Microbiol. 2008, 67, 947-957. [CrossRef] [PubMed]

29. Matschiner, J.T.; Amelotti, J.M. Characterization of vitamin K from bovine liver. J. Lipid Res. 1968, 9, 176-179. [CrossRef]

30. Dunphy, P.J.; Phillips, P.G.; Brodie, A.F. Separation and identification of menaquinones iron microorganisms. J. Lipid Res. 1971, 12, 442-449. [CrossRef]

31. Collin, M.D.; Shah, H.; Minnikin, D.E. A note on the separation of natural mixtures of bacterial menaquinones using reverse phase thin-layer chromatography. J. Appl. Bacteriol. 1980, 48, 277-282. [CrossRef]

32. Suvarna, K.; Stevenson, D.; Meganathan, R.; Hudspeth, M.E.S. Menaquinone (vitamin k 2) biosynthesis: Localization and characterization of the mena gene from Escherichia coli. J. Bacteriol. 1998, 180, 2782-2787. [CrossRef]

33. Ramsey, M.; Hartke, A.; Huycke, M. The physiology and metabolism of enterococci. In Enterococci: From Commensals to Leading Causes of Drug Resistant Infection; Gilmore, M.S., Clewell, D.B., Ike, Y., Shankar, N., Eds.; Massachusetts Eye and Ear Infirmary: Boston, MA, USA, 2014; pp. 581-635.

34. Huycke, M.M.; Moore, D.; Joyce, W.; Wise, P.; Shepard, L.; Kotake, Y.; Gilmore, M.S. Extracellular superoxide production by Enterococcus faecalis requires demethylmenaquinone and is attenuated by functional terminal quinol oxidases. Mol. Microbiol. 2001, 42, 729-740. [CrossRef] [PubMed]

35. Winstedt, L.; Frankenberg, L.; Hederstedt, L. Enterococcus faecalis V583 contains a cytochrome bd-type respiratory oxidase. J. Bacteriol. 2000, 182, 3863-3866. [CrossRef]

36. Baureder, M.; Hederstedt, L. Genes important for catalase activity in Enterococcus faecalis. PLoS ONE 2012, 7, e36725. [CrossRef]

37. Garrigues, C.; Loubiere, P.; Lindley, N.D.; Durand, G. Control of the shift from homolactic acid to mixed-acid fermentation in Lactococcus lactis: Predominant role of the NADH/NAD ratio. J. Bacteriol. 1997, 179, 5282-5287. [CrossRef]

38. Koebmann, B.; Blank, L.M.; Solem, C.; Petranovic, D.; Nielsen, L.K.; Jensen, P.R. Increased biomass yield of Lactococcus lactis during energetically limited growth and respiratory conditions. Biotechnol. Appl. Biochem. 2008, 50, 25-33. [CrossRef] [PubMed]

39. Yamamoto, Y.; Gaudu, P.; Gruss, A. Oxidative stress and oxygen metabolism in lactic acid bacteria. In Lactic Acid Bacteria and Bifidobacteria Current Progress in Advanced Research; Sonomoto, A.Y.K., Ed.; Caister Academic Press: Norfolk, UK, $2011 ;$ pp. 91-102.

40. Mazzeo, M.F.; Cacace, G.; Peluso, A.; Zotta, T.; Muscariello, L.; Vastano, V.; Parente, E.; Siciliano, R.A. Effect of inactivation of ccpA and aerobic growth in Lactobacillus plantarum: A proteomic perspective. J. Proteomics 2012, 75, 4050-4061. [CrossRef]

41. Eikmeyer, F.G.; Heinl, S.; Marx, H.; Pühler, A.; Grabherr, R.; Schlüter, A. Identification of oxygen-responsive transcripts in the silage inoculant Lactobacillus buchneri CD034 by RNA sequencing. PLoS ONE 2015, 10, e0134149. [CrossRef]

42. Ricciardi, A.; Ianniello, R.G.; Parente, E.; Zotta, T. Factors affecting gene expression and activity of heme- and manganesedependent catalases in Lactobacillus casei strains. Int. J. Food Microbiol. 2018, 280, 66-77. [CrossRef]

43. Zhang, Y.; Li, Y. Engineering the antioxidative properties of lactic acid bacteria for improving its robustness. Curr. Opin. Biotechnol. 2013, 24, 142-147. [CrossRef] [PubMed]

44. An, H.; Zhou, H.; Huang, Y.; Wang, G.; Luan, C.; Mou, J.; Luo, Y.; Hao, Y. High-level expression of heme-dependent catalase gene katA from Lactobacillus sakei protects Lactobacillus rhamnosus from oxidative stress. Mol. Biotechnol. 2010, 45, 155-160. [CrossRef] [PubMed]

45. Zotta, T.; Ricciardi, A.; Guidone, A.; Sacco, M.; Muscariello, L.; Mazzeo, M.F.; Cacace, G.; Parente, E. Inactivation of ccpA and aeration affect growth, metabolite production and stress tolerance in Lactobacillus plantarum WCFS1. Int. J. Food Microbiol. 2012, 155, 51-59. [CrossRef]

46. Igarashi, T.; Kono, Y.; Tanaka, K. Molecular cloning of manganese catalase from Lactobacillus plantarum. J. Biol. Chem. 1996, 271, 29521-29524. [CrossRef] [PubMed]

47. Watanabe, M.; van der Veen, S.; Nakajima, H.; Abee, T. Effect of respiration and manganese on oxidative stress resistance of Lactobacillus plantarum WCFS1. Microbiology 2012, 158, 293-300. [CrossRef] [PubMed]

48. Berlec, A.; Škrlec, K.; Kocjan, J.; Olenic, M.; Štrukelj, B. Single plasmid systems for inducible dual protein expression and for CRISPR-Cas9/CRISPRi gene regulation in lactic acid bacterium Lactococcus lactis. Sci. Rep. 2018, 8, 1-11. [CrossRef]

49. Tan, S. A modular polycistronic expression system for overexpressing protein complexes in Escherichia coli. Protein Expr. Purif. 2001, 21, 224-234. [CrossRef]

50. Kim, K.-J.; Kim, H.-E.; Lee, K.-H.; Han, W.; Yi, M.-J.; Jeong, J.; Oh, B.-H. Two-promoter vector is highly efficient for overproduction of protein complexes. Protein Sci. 2004, 13, 1698-1703. [CrossRef] 